\title{
4. The mechanisms of food waste prevention: theory, design, and practice for changing behaviours
}

\author{
Simone Busetti and Bruno Dente
}

\section{INTRODUCTION}

There is growing international attention to food waste as an environmental, health, economic and social problem. Depletion of resources in producing food and the environmental and economic costs of discarding waste combined with the social, ethical and symbolic values of wasting food, while poverty and hunger are still a global issue.

The two 2008 crises - the global food crisis and the most renowned financial crisis - have changed public attitudes towards food. Old certainties about food commodities and security were disrupted and food got new public attention, no longer as a moral issue towards developing countries, but as an internal security problem threatening the Western world (Collier, 2008; McMichael, 2009; Lang, 2010). Such developments certainly provided a favourable context for food sustainability, one where wasting food was considered less desirable and harder to afford and where policy measures tackling food waste could enjoy new visibility and global attention (Evans, Campbell and Murcott, 2013; Manzocco et al., 2016).

In 2015, in fact, the UN adopted the 17 Sustainable Development Goals, which included a specific commitment to halve food waste at the retail and consumer levels and reduce food losses along production and supply chains, including a commitment to address post-harvest losses (United Nations, 2015). Similarly, the 2014 Commission Communication promoting a zero-waste programme for Europe and the following 2015 Action Plan for the Circular Economy paid specific attention to food waste, in particular for improving measurement, date marking, food recovery and donation. In 2016, three EU countries - Italy, France and Romania - passed legislation for reducing food waste.

If - as it appears - the time has come for action, the evidence base is still uncertain. As agreed by several commentators, how food waste prevention 
works, how it is implemented, and how impacts are produced, remain unclear, mostly because of a lack of comparable data, the paucity of evaluations, and the relative novelty of such measures (Cox et al., 2010; Thyberg and Tonjes, 2016). With the ambition of partially remedying these gaps, the chapter provides an analysis of the Italian food waste policy, aimed at reconstructing its underlying causal mechanisms.

The analysis is interesting in at least two respects. First, Italy has a consolidated experience in tackling food waste. For a long time it was the only EU country with a 'Good Samaritan Law' and one among the few with tax benefits on donations (Visschers, Wickli and Siegrist, 2016; Baglioni, de Pieri and Tallarico, 2017). Further, the 2016 reform introduced innovative measures - such as the possibility to donate food beyond the 'best-before' date - that have a central place in the debate on reforming food waste (FUSIONS, 2016a). Second, the causal logic of many of these measures seems simple and straightforward and such apparent simplicity can further highlight the importance of an approach based on causal mechanisms, as a way to identify the implicit assumptions of policy designs, the contextual features supporting - or impeding - their working, and the conditions for possible replicability.

In conducting the analysis, we took the same approach of our previous work on 'mechanism-based design', stressing the importance of switching from a tool-centred to a mechanism-centred approach to designing (and analysing) policies (Busetti and Dente, 2018). The chapter makes a review of academic literature, newspapers, government documents and grey literature. In completing this review, we took inspiration from the method of realist synthesis (Pawson, 2002, 2006) a qualitative review aimed specifically at reconstructing causal mechanisms. Three in-depth interviews with one policy-maker, a food redistribution organization, and an expert were then performed in order to discuss findings.

The chapter proceeds with five main sections. The first provides a brief introduction to food waste by paying specific attention to drivers and policies. The second presents the Italian policy for reducing food waste. The third provides a brief introduction to the use of causal mechanisms for designing and analysing policies, while the following two sections analyse two of the new measures introduced in 2016: bureaucratic simplifications and the permission to donate food once it has passed the best-before date.

\section{PREVENTING FOOD WASTE: A BRIEF REVIEW}

There is a recurrent distinction in the literature between food loss and food waste (Parfitt, Barthel and Macnaughton, 2010; Manzocco et al., 2016; Thyberg and Tonjes, 2016). Food loss generally refers to edible material lost in producing, processing and preparing food, whereas food waste indicates all 
food produced for human consumption, but then discarded or not consumed. The two terms partly overlap and do not provide a clear distinction between edible and non-edible material, which is, however, fundamental when it comes to designing policies for contrasting food waste.

With these shortcomings in mind, Garrone, Melacini and Perego (2014a) start with the concept of 'food availability' - that is, all food produced - and then distinguish that into either food scrap, surplus food or consumed food. Food scrap includes non-edible food, such as production-line leftovers at the manufacturing stage, damaged products below quality standards (e.g., melted ice cream), and non-edible parts of food (e.g., vegetable peel). Surplus food is instead edible food that is produced, manufactured, retailed, or served, but for several reasons ends up not sold or consumed by the intended customer. Finally, consumed food is the one delivered through the traditional market and consumed by humans. Following this distinction, policies contrasting food waste should target surplus food (either lost or wasted) and pursue two prevention goals: reducing total surplus and ensuring that most surplus will be recovered for feeding humans (and not to go to the landfill or be used for animal feed).

Beginning with the reduction of total surplus, related policies are varied and run the whole spectrum of policy instruments. Consumers are typical targets of awareness campaigns and education measures promoting new skills of food preparation, reuse, and storage (Hebrok and Boks, 2017). Similar effects can also be achieved in food services, also by nudging customers in order to induce less wasteful practices of displaying, serving and portioning (Kallbekken and Sælen, 2013). The remodulation of waste fees towards 'pay-as-you-throw' schemes is a typical negative incentive that can make producers and retailers change marketing and organizational routines in order to reduce disposal costs (Mena, Adenso-Diaz and Yurt, 2011; Garrone, Melacini and Perego, 2014b). Producers may also be the target of positive incentives, however, such as subsidies to encourage the introduction of new technologies like advanced packaging systems or selective fishing gears that reduce by-catch (FUSIONS, 2016b). Finally, regulation can support surplus reduction in several ways, by introducing new quality regulations in agriculture (FUSIONS, 2014) or new labelling standards (European Commission, 2018).

Although policy-makers are beginning to experiment with such a diverse mix of policies, determinants of food surplus are hard to address. Food has been wasted throughout all civilization, but in the past most wastage was for reasons not controlled by people, such as bad weather, deficient infrastructure, and lack of technologies (Schneider, 2013). Today, new technological, institutional and social drivers add to old motives and affect the behaviours of producers, retailers and consumers (FUSIONS, 2014). Growth in consumption (Thøgersen, 1996), low cost of food (Visschers et al., 2016), dietary transition towards healthy (and perishable) food (Parfitt et al., 2010), wasteful marketing 
strategies (Aschemann-Witzel et al., 2015) and serving practices (Thyberg and Tonjes, 2016) are only some among the many determinants of surplus food.

Beretta et al. (2013) distinguish avoidable, possibly avoidable, and unavoidable losses. The first regards phenomena such as overbuying, overcooking, and poor storage, but also overproduction, unharvested crops, suboptimal processing, and unsold products. Possibly avoidable losses are those related to taste, aesthetic preferences, lack of demand and quality standards not regarding safety or health, but are nonetheless rooted in consumers' preferences. Finally, unavoidable losses involve mainly non-marketed food from production and processing notwithstanding the use of best-available technologies (such as in the case of seasonality and unpredictable demand fluctuations; Mourad, 2016).

One cannot fail to see that even the 'easy' case - avoidable losses - requires demanding technological, organizational and behavioural changes. If one adds the difficult cases, it is undisputable that - even with the introduction of rigorous prevention programmes - the amount of surplus food will nonetheless be considerable (Manzocco et al., 2016; Thyberg and Tonjes, 2016). This introduces the second goal of prevention policy, that is, ensuring that existing surplus is recovered and used for feeding humans. In the perspective of a systematic amount of 'unavoidable losses', in fact, policies supporting donation, recovery and redistribution are not residual instruments of inefficient production systems, but fundamental tools of food waste prevention.

In the case of donations, policies aim at either creating incentives or removing barriers to donations. Concerning the former, typical measures include VAT exemption on donated products (FUSIONS, 2016b), tax credits and tax deductions (FUSIONS, 2016a). As mentioned, fiscal incentives can be coupled with the remodulation of waste fees through pay-as-you-throw schemes, which can increase the economic advantage of donations over disposal (Visschers et al., 2016). Good Samaritan Laws are instead a typical way of removing barriers (Baglioni et al., 2017; Priefer, Jörissen and Bräutigam, 2016). Under such laws, donors' liability for donated products ends once non-profit organizations collect the food. The law works as a legal protection for donors who are not responsible for the consequences of the potential mismanagement of their products. Finally, another typical barrier regards limits on the types of food that can be donated. Regulations permitting donations of mislabelled food or food past its best-before date are good examples of enlarging the range of donatable products. 


\section{THE ITALIAN POLICY FOR PREVENTING FOOD WASTE: A BRIEF HISTORY}

Italy has a rather long policy history of preventing food waste, with the introduction of the first incentives to donors dating back to the late 1990s and subsequent additions and improvements until the last reforms in 2016.

Concerning incentives, the first fiscal benefits were introduced in 1997, when Law 441 included donations among VAT-exempted operations. The same year, Law 460/1997 clarified that donations were not part of company profits and, in 1999, Law 113 established that donated goods were to be considered as destroyed, and hence suitable for a VAT deduction. Finally, a further economic incentive was provided in 2005, when Law 80/2005 established that donations could be partly deducted from taxable income.

Although the mix of incentives may appear rich, they are the same of goods gone unsold or destroyed, and hence donations do not enjoy a special fiscal advantage over disposal (PINPAS, 2015; Baglioni et al., 2017). Furthermore, Italian municipal waste fees are generally based on size and hence independent of the amount of food actually disposed of (or recovered). Interestingly, the 2016 reform introduced the possibility for municipalities to establish discounts on waste fees on the base of food donations, but both the novelty of the reform and the fact that only a few cities are introducing such discounts make it difficult to evaluate their effects.

A second relevant feature of the Italian food waste policy regards donors' liability for donations. In 2003, Law 155/2003 made a major leap, by establishing that - concerning conservation, transport, storage and usage of donated food products - non-profit organizations distributing food for free to disadvantaged people were to be considered equal to final consumers. It is a typical 'Good Samaritan Law', determining the legal responsibility of food distribution organization for the safety of donated food products and freeing donors from all liability subsequent to donations. Donors remain responsible for the production and transformation phases and have to donate safe products, but are protected if non-profit organizations misuse donations. Further, the equivalence to final consumers eliminated several bureaucratic burdens for non-profit organizations (which in their food-related activities have the same status of 'consumers' instead of that of professionals).

The law was considered fundamental in smoothing the donation process, especially for those products donated by supermarkets and canteens, which have shorter lives and need quick recovery. It is in fact no coincidence that it was right in 2003 that the biggest Italian food recovery and distribution charity - Banco Alimentare - could start Siticibo, a new programme of local recovery especially dedicated to supermarkets and canteens. ${ }^{1}$ Following the law, also in 
2003, Coop - a large cooperative of Italian supermarkets - started its corporate programme to prevent food waste.

In 2014, the Ministry of the Environment approved the National Plan for Food Waste Prevention (PINPAS), which contained ten priority actions for reducing surplus food (Ministero dell'Ambiente, 2014). Following the PINPAS, a consultation initiative was launched and a position paper was published collecting critical points and proposals for further reform (PINPAS, 2015). Among the several proposals for change, the most notable were the possibility to donate food beyond the best-before date, a streamlining of bureaucratic procedures, the possibility to have discounts on waste fees to account for donations and the inclusion of private organizations as possible recipients of food donations.

In the favourable context of the Milan Expo 2015 (which was dedicated to food), a new law including all the mentioned proposals was approved (Law 16/2016). Regarding the streamlining of bureaucratic burdens, it established that communications to the fiscal authority registering donations were to be sent once a month, as a monthly summary communication for all donations performed within the month. It was a striking simplification with respect to the former system, in which donors were obliged to produce communications for each single donation and with a five-day advance. Concerning the quality of donations, the law significantly enlarged the range of products admitted, including confiscated and mislabelled goods, and bread after 24 hours of its baking. Most importantly, the law introduced the possibility to donate food beyond the best-before date.

Although the implementation of the law is in its infancy, it has received an incredibly positive coverage by the media (Rubino, 2017), policy-makers (Gadda, 2018) and stakeholders (see the several comments in Toia, 2018), all claiming the almost immediate success of the policy. More reliable data is certainly needed for a proper appraisal of its effects, but an analysis of causal mechanisms can provide useful insights into how the policy works and how its design features may (or may not) be responsible for the claimed success.

\section{A MECHANISM-BASED ANALYSIS OF FOOD WASTE POLICY}

Policy programmes are always based on some causal hypothesis on how design features can change a certain undesirable condition. Such causal logic is usually implicit and not fully articulated in the policy statute. In its basic form, the logic resembles an if-then model, in which the known factors are design features and desired outcomes (e.g., if design features, then desired outcome).

In the food waste policy described above, the design features are mainly of three kinds: bureaucratic simplifications, economic incentives, and permission 
to donate new products. In this case, a basic if-then hypothesis would read as follows: if bureaucratic simplifications and economic advantages are provided and new products are admitted to donation, then more food will be donated, recovered, and redistributed for human consumption.

The logic makes immediate sense. It is simple, direct, and there are apparently no holes in the causal chain. It has, however, one major miss: there is in fact no explicit mention of the actors of the policy. Design features are supposed to act on certain actors who are supposed to react by increasing donations, recovery and redistribution. These actors nonetheless have their goals, preferences, routines and skills that interact with the design of the policy and may impede or reinforce the expected change of behaviour. Even when the policy may look incredibly advantageous and actors' reactions are almost certain, in fact an explicit in-depth analysis of how actors respond to design features may reveal unexpected interactions and unpredicted causal paths.

In the case of food waste, design features should ensure that former donors donate more food, that new donors start donating, and that non-profit organizations recover and distribute donations. In order to do so, they should trigger a certain causal mechanism that changes actors' behaviour in a way congruent with the goals of the policy. In this respect, the correct prediction of the causal mechanism that - given certain contextual conditions - may trigger such response is fundamental. In fact, it is in starting with this prediction that designers should build their designs. These should in fact include a hypothesis of the possible causal interaction between design features, actors and context, understanding which causal mechanisms could work, which design features may trigger that mechanism, which actors respond and how, and how contextual conditions may support or hinder such response.

The following analysis is divided into two sections that investigate two simple design features introduced by the 2016 reform: bureaucratic simplifications and the possibility to donate food after the best-before date (BBD). The two are supposed to work by triggering trivial causal mechanisms. Bureaucratic simplifications cut the costs of donation and hence make donors increase or start donations. The BBD innovation expands the types of products that can be donated and hence enlarge the set of actions available to donors, who can eventually donate all the surplus that they were previously forced to waste. Both mechanisms make immediate sense, and it seems almost self-evident that those design features will trigger those mechanisms and produce the reactions described. Unfortunately, however, their causal logic is only partially correct and this is mainly because the causal power of actors' responses and context conditions have been largely disregarded. 


\section{CUT THE COSTS AND DONATIONS WILL GROW}

Bureaucratic simplifications are supposed to trigger a simple mechanism of cost-benefit calculation. As long as the benefits are larger than the costs, so the logic goes, donors will prefer donating and more food will be recovered and redistributed. Cutting the costs is hence a fundamental lever for increasing donations and the 2016 reform did so by profoundly streamlining procedures for fiscal communications. Although everyone would generally agree with this logic, several qualifications are in order, mainly related to two elements: the diversity of donors and the recovery ability of charities.

First, one should consider that donating is costly. Donors have to change their procedures for product disposal, make an agreement with a non-profit organization (or organize donations case-by-case), provide a space for storing donations and have some employees working on the donation process (i.e., selecting and storing products). Also, if donors want to enjoy existing tax benefits, they have to record their donations and send communications to the fiscal authority. Briefly put, a procedure additional to that of disposal should be introduced and this will be more or less expensive depending on the quality of donations. In fact, costs will rise if donations need special management (e.g., refrigerators) or if they include one or a variety of products (i.e., if different management procedures are required for the products to be donated).

Combining these elements, two opposite prototype donors can be imagined. At one extreme, big manufacturing companies donating large amounts of homogeneous products will incur less costs and have all the management and administrative capacity to perform donations. At another extreme, small retail shops with small amounts of heterogeneous surplus will have high costs and a far smaller capacity to manage the donation procedure. Accordingly, a 2016 study by Coop reported that, even if 75 per cent of its affiliates participated in the corporate programme of donations, participation depended significantly on shop size, with 100 per cent of hypermarkets engaged in the programme and much lower participation rates for smaller shops (Coop, 2016). Similarly, when surveying the management of food surplus by hotels, Pirani and Arafat (2016) reported that the main reason for not donating was that surplus was not enough to justify initiating a donation procedure.

Interestingly, the new fiscal communication - quite a simple design feature that uniformly reduces costs - interacts differently with such diverse targets. As mentioned, before the 2016 reform, there was the need for fiscal documents to be communicated for each donation and with a five-day advance. It was a system made precisely for big donors, who could bear all the logistic and administrative costs and could plan large one-off donations in advance. In this respect, the introduction of monthly summary communications - although 
certainly beneficial - was not particularly relevant for such donors who could keep on with the former system.

Instead, the new procedure was apparently decisive for small operators with diversified surplus, who have neither the capacity nor the quality of surplus that could permit compliance with the former procedure. Storing different products for donation in a little supermarket and keep them there for five days was simply impossible. In this respect, the new procedure removed a fundamental barrier to donations. Not surprisingly, in fact, in commenting on the 2016 reform, the Coop manager recognized the fundamental role of bureaucratic simplifications, which permitted a more complete, systematic and consistent donation activity, in particular for those small supermarkets that could not comply with previous procedures (Bruzzone, 2018).

Let us now assume that the policy works and our small supermarket decides to start donating its surplus. In order to do so, it has to contact a non-profit organization and make an agreement for planning the collection of its surplus. The policy has no design feature directly targeting food redistribution organizations, apparently assuming that new donations will automatically be recovered.

However, the recovery ability of charities is a fundamental point in the analysis of the causality of bureaucratic simplification. Increased donations will increase costs for charities, and these costs also depend on the quality of such donations. Garrone et al. (2014a) talk of a degree of recoverability that depends on management intensity (such as maintenance or transportation) and intrinsic recoverability (such as shelf life). Charities will not be indifferent to the costs and quality of donations, but will obviously prefer food surplus with high intrinsic recoverability and low management intensity.

In this respect, the big manufacturing company - our 'easy donor' - also permits easy recovery. It provides a great quantity of homogeneous food through large one-off donations and entails low management costs for charities. Small donors with variable products offer instead low amounts of surplus that require high management costs, such as selection activities and higher costs of transport. As confirmed by Alexander and Smaje (2008), a back-of-store collection - necessary to engage small retailers - imposes considerable costs and is likely to yield poor-quality donations (i.e., varied and with short shelf life).

Following this reasoning, the causality of bureaucratic simplifications depends not only on donors' costs and capacity, but also on the capacity (and will) of charities, a capacity that the policy apparently considers as a given. The organization of efficient local networks of collection and redistribution, possibly with neighbourhood hubs and just-in-time and km0 (zero kilometre) recovery and delivery, is fundamental for collecting small donors' surplus. However, it is not necessarily given in any context. Although bureaucratic simplifications may actually help in removing barriers for small donors, there is no design feature in the policy that can make back-of-store recoveries more 
appealing. Examples of auxiliary design features that may conserve the mechanism at its full working capacity include direct support to charities (as established in some Italian regional laws on food donation) or partnering charities in the creation of local networks (as is now being experimented with in Milan).

To conclude this section, although bureaucratic simplifications are supposed to work by cutting costs, they do not so in a linear and straightforward way. Depending, in fact, on donors' capacity, the mechanism can be largely neutralized (as for big manufacturers) or magnified (as for small retailers). Moreover, the fundamental interaction with the capacity of charities may ultimately hamper the full working capacity of the (possibly) activated mechanism.

\section{THE SHELF-LIFE GAME AND THE REPUTATION GAME}

The second feature of interest is the possibility of donating food once it has passed its best-before date (BBD). Again, the causal mechanism supposedly triggered is simple. Although it may not be at its best, food after the BBD is edible and safe, but unmarketable. Opportunity to donate this food would possibly divert large amounts of food from disposal to donation, extending food life beyond its market value. In fact, thanks to the new rule, donors will - at last - be able to donate all the food that they were unfortunately forced to waste following previous regulations.

A preliminary test of the causal relevance of this design feature relates to the actual amount of food that is disposed of because it has passed the BBD. Such data are not directly available, but some information can be extrapolated by looking at the sources of surplus food produced by potential donors (Garrone et al., 2014b). For manufacturing companies, food surplus is generated mainly because it has reached the internal sell-by date (66.9 per cent of total surplus), which is normally set at one-third of the entire shelf life of the product. Other reasons for food surplus are non-compliance with commercial standards, such as aesthetic criteria (12.2 per cent), product refusal (9.1 per cent), packaging non-compliance (5.7 per cent) and returns of unsold products (6.1 per cent). Only in this latter case (and partly in product refusal for the chilled segment), surplus would include food beyond the BBD. All other sources of surplus are made of food well below that date and hence perfectly available for high-quality donation.

Retail distribution centres have the following dynamic of food surplus generation: internal sell-by date reached (48.7 per cent), returns of unsold products (28.1 per cent), product non-compliance (12.8 per cent), packaging non-compliance (10.4 per cent). No reliable quantitative data were available for retail stores, however, but the main reason reported was related to sell-by date (in a different study the same authors also mention package damages; see Garrone et al., 2014a). Although naturally provided with a shorter life with 
respect to surplus in manufacturing companies, most of these products will have not passed the BBD.

Overall, these results signal that the supply of food beyond the BBD may be relatively small, so limiting the scope of the new rule. One may certainly agree that this is not a major issue and that the more food is recovered, the less resources are wasted and the more disadvantaged people may be helped. Let us see then how donors and recovery organizations use this rule in practice.

A possible hypothesis is that the two play a 'shelf-life game', that is, a sort of zero-sum game in which donors and charities are one against the other. Since donations are a loss and a missed revenue, donors would try to sell their products until the very last day of market utility - that is, until the BBD. On the opposite side, non-profit organizations will try to recover food as early as possible, in order to have time for redistribution and to deliver high-value food to beneficiaries. According to the game, donors would respond enthusiastically to the new rules, whereas charities will fear to receive lower-quality donations and may largely prefer not collecting this food. Let us see how the game works in practice.

Concerning retailers, the outlined strategy is possibly correct. In studying retailers' practices, Alexander and Smaje (2008) revealed that retailers followed a normative hierarchy in which donations were rated fifth after 'sell to customer', 'sell to customer at a reduced price', 'use in staff restaurant', 'sell to staff'. Promotions for food close to its BBD or reuse options of damaged food (such as for preparing new products like chopped fruits) are now frequent strategies in retailing, which certainly help in both reducing waste and extracting profits from potential surplus. When the BBD has finally come, the product is donated or disposed of.

For manufacturers, a completely different strategy seems to be at work. In fact, manufacturers have their names on donated products and hence are particularly sensitive to the reputational consequences of donations. They fear that donations backfire and adversely affect - instead of enhance - their reputation (Baglioni et al., 2017). This, in fact, can happen for several reasons. In the worst case, donated food could be mismanaged and harm beneficiaries; in the best, news that the company gives its 'leftovers' to disadvantaged people may certainly not enhance its social image. Interestingly, notwithstanding the possibility provided by the law, manufacturers will resist the new rule and avoid donating food after its BBD.

As De Boeck et al. (2017) put it, the interface between donors and non-profit organizations is key in this respect, since the development of a trusted relationship could be fundamental for smoothing the donation process. Interestingly, in the case of Banco Alimentare - the largest food redistribution organization in Italy - not only do manufacturers not provide food past the BBD, but they also make periodic inspections to the warehouses of the charity in order to ensure that their products are managed according to the highest standards. 
Cognizant of the importance of conserving donors' trust, Banco Alimentare also performs several inspections of the canteens and associations to which it provides food, to be sure that no mismanagement may occur and donors' reputations are kept intact. Notice, however, that such professional management is not to be expected of all food redistribution organizations, so that one may assume manufacturers to be generally very cautious about their donations.

Concerning how charities will respond to the new rule, consider first that recovered surplus can be used either for preparing meals in social canteens or for preparing food aid packs. In order to provide high-value support to disadvantaged people, organizations distributing packs collect only food with a long shelf life, and hence would not accept products after the BBD. These organizations, moreover, incur reputational risks similar to those of manufacturers, since distributing food past the BBD is seen as potential damage to the image of the charity (Lopasso, 2017). For organizations preparing meals, the $\mathrm{BBD}$ is not visible and hence more flexibility is to be expected. However, the shorter the shelf life, the more capacity is needed on the part of charities, who will have to set up a quick - if not just-in-time - collection and delivery. Again, such capacity is not necessarily available for all charities and this may hamper the actual utility of donations of food after their BBD.

To conclude this section, as simple as the mechanism may appear, its causal logic is possibly flawed. The market for food beyond the BBD is in fact limited, because of lack of both its supply and demand. While retailers may (marginally) shift their donation dates thanks to the new rules, manufacturers will refrain from donating food that could possibly damage their reputation. Charities will not be particularly favourable either, because of the preference for high-value food, risk aversion, and possible lack of capacity. As shown in the case of Banco Alimentare, donors and charities do not play an adversarial 'shelf-life' game, but a largely cooperative reputational game.

\section{CONCLUSIONS}

As simple and predictable as the two design features might have appeared at the beginning, they revealed a complex causality. Unforeseen actors' preferences, their (lack of) resources and some relevant contextual conditions interact with the design of the policy and alter its ability to trigger the hypothesized causal mechanisms. The analysis has certainly great explanatory power. It highlights how features such as the capacity of donors, the recovery skills of charities, and the reputational risks incurred by both actors may importantly affect the implementation of the policy. These elements are not directly under the control of designers, but they are nonetheless fundamental for ensuring that design features successfully trigger a causal mechanism and produce the expected changes of behaviour. 
Following this reasoning, the first advantage of an approach based on causal mechanisms is that it permits focusing designs on a fuller understanding of the causal relations actually in place. The analysis can in fact provide a useful guideline for designers, by suggesting by which mechanism actors might change their behaviours and highlighting which design features and contextual conditions may trigger and support that mechanism. In this respect, in the two examples described above, some important causal factors were certainly underestimated, following the faulty assumption that the design of the policy would have been sufficient to change actors' behaviours.

As well as helping in the crafting of new policies, this analysis would also show how existing designs may be complemented and reformed, for instance by adding new design features that may be needed in order to support and conserve the triggered mechanisms. Concerning the case of food donations, the creation of local networks of collection and delivery seems a promising auxiliary feature that may help sustain the behaviours triggered by the hypothesized causal mechanisms. Such a local network could, in fact, support both the recovery from small donors and the quick use of food beyond its BBD for canteens preparing meals. Similarly, the analysis shows that the causal mechanism of the BBD rule is largely neutralized by the reputational worries of both donors and charities. In this case, designers may wonder which auxiliary design features might help in protecting their reputation (and not only their legal responsibility, as both the BBD and the 'Good Samaritan Law' do).

A third point is the ability of such an approach to provide suggestions on the actual working of the policy. Outcomes of food waste policies are difficult to investigate, since reliable data are largely absent, there are few evaluations and many of these interventions are relatively young. It is no surprise that improving measurement is a typical claim in any proposal for reforming the policy. Interestingly, however, the analysis provided here can give several insights into appraising whether the policy is working. When analysing impacts, it is almost a conditioned reflex to state that correlation is not causation and that correlations should be supported by a causal mechanism. Investigating such mechanisms can provide interesting insights into the possible impacts of the policy, showing which results are likely, which are not, and which design features would be responsible for those impacts.

If our analysis of food waste policy is correct, bureaucratic simplifications will mostly work for small donors and depending on the collection capacity of charities. The rule admitting donations of food past the BBD would instead face strong limits in its implementation, because the supposed causal mechanism is not supported by congruent behaviours by most implementers. Notice that we are not saying that the 2016 reform does not deserve the positive coverage reported above. However, our analysis reminds us to be cautious since the actual operation of the mechanisms supposedly triggered by two of its most 
prominent design features have revealed severe limitations. In this regard, for instance, the special context in which the reform was born - that is, the major focusing event produced by the Universal Exposition, 'Feeding the Planet, Energy for Life', held in Milan in 2015 - might probably be worth investigating for its effects in raising awareness and provide a strong springboard that possibly pushed the policy beyond the scope of its sole design features.

\section{NOTE}

1. From its start in 2003, thanks to Siticibo, amounts of recovered bread, fresh fruits, and prepared meals kept increasing with impressive growth rates, with fresh fruits - a food that is normally hard to recover - passing from $17425 \mathrm{~kg}$ in 2004 to 156 $758 \mathrm{~kg}$ in 2012 (Banco Alimentare, 2013).

\section{REFERENCES}

Alexander, C. and C. Smaje (2008), 'Surplus retail food redistribution: An analysis of a third sector model', Resources, Conservation and Recycling, 52(11), 1290-98.

Aschemann-Witzel, J., I. de Hooge and P. Amani etal.(2015), 'Consumer-related food waste: Causes and potential for action', Sustainability, 7(6), 6457-77.

Baglioni, S., B. de Pieri and T. Tallarico (2017), 'Surplus food recovery and food aid: The pivotal role of non-profit organisations: Insights from Italy and Germany', VOLUNTAS: International Journal of Voluntary and Nonprofit Organizations, 28(5), 2032-52.

Banco Alimentare (2013), La Legge 155/2003, una legge italiana all'avanguardia al fine di incoraggiare le donazioni di cibo cotto e fresco ai più pover [Law 155/2003, An Italian Law to Enhance Donations of Fresh and Cooked Food for the Poor], accessed 9 October 2018 at https:/www.bancoalimentare .it/sites/bancoalimentare.it/old-files/Legge_155_20032(2).pdf.

Beretta, C., F. Stoessel, U. Baier and S. Hellweg (2013), 'Quantifying food losses and the potential for reduction in Switzerland', Waste Management, 33(3), 764-73.

Bruzzone, M. (2018), 'Coop: Un volano per far crescere le donazioni' [Coop: A flywheel to make donations grow], in P. Toia, Dallo spreco al dono, pp. 34-5 [e-book], accessed 9 October 2018 at http://www.patriziatoia.info/ images/ebooks/Dallo_spreco_al_dono.pdf.

Busetti, S. and B. Dente (2018), 'Designing multi-actor implementation: A mechanism-based approach', Public Policy and Administration, 33(1), 46-65.

Collier, P. (2008), 'The politics of hunger - how illusion and greed fan the food crisis', Foreign Affairs, 87(6), 67-79. 
Coop (2016), Libro bianco Coop sullo spreco alimentare [White Paper on Food Waste], accessed 9 October 2018 at http://coopnospreco.it/images/ libro_bianco_ancc_coop.pdf.

Cox, J., S. Giorgi and S. Sharp et al. (2010), 'Household waste prevention a review of evidence', Waste Management and Research, 28(3), 193-219.

De Boeck, E., L. Jacxsens, H. Goubert and M. Uyttendaele (2017), 'Ensuring food safety in food donations: Case study of the Belgian donation/acceptation chain', Food Research International, 100, 137-49.

European Commission (2018), Market Study on Date Marking and Other Information Provided on Food Labels and Food Waste Prevention, accessed 9 October 2018 at https://publications.europa.eu/en/publication-detail/-/ publication/e7be006f-0d55-11e8-966a-01aa75ed71a1/language-en.

Evans, D., H. Campbell and A. Murcott (2013), 'A brief pre-history of food waste and the social sciences', The Sociological Review, 60(S2), 5-26.

FUSIONS (2014), Drivers of Current Food Waste Generation, Threats of Future Increase and Opportunities for Reduction, accessed 9 October 2018 at https://www.eu-fusions.org/index.php/publications.

FUSIONS (2016a), Recommendations and Guidelines for a Common European Food Waste Policy Framework, accessed 9 October 2018 at https://www.eu -fusions.org/index.php/publications.

FUSIONS (2016b), Market-based Instruments and Other Socio-economic Incentives Enhancing Food Waste Prevention and Reduction, accessed 9 October 2018 at https://www.eu-fusions.org/index.php/publications.

Gadda, M.C. (2018), 'L'effetto più importante? L'impatto culturale' [The biggest effect? The cultural impact], in P. Toia, Dallo spreco al dono, pp. 34-5 [e-book], accessed 9 October 2018 at http://www.patriziatoia.info/ images/ebooks/Dallo_spreco_al_dono.pdf.

Garrone, P., M. Melacini and A. Perego (2014a), 'Opening the black box of food waste reduction', Food Policy, 46, 129-39.

Garrone, P., M. Melacini and A. Perego (2014b), 'Surplus food recovery and donation in Italy: The upstream process', British Food Journal, 116(9), 1460-77.

Hebrok, M. and C. Boks (2017), 'Household food waste: Drivers and potential intervention points for design - an extensive review', Journal of Cleaner Production, 151, 380-92.

Kallbekken, S. and H. Sælen (2013), “"Nudging” hotel guests to reduce food waste as a win-win environmental measure', Economics Letters, 119(3), 325-7.

Lang, T. (2010), 'Crisis? What crisis? The normality of the current food crisis', Journal of Agrarian Change, 10(1), 87-97.

Lopasso, S. (2017), 'Implementazione ed effetti della legge Gadda sullo spreco alimentare' [Implementation and effects of the Gadda law on food waste], degree dissertation, Università di Milano-Bicocca. 
Manzocco, L., M. Alongi, S. Sillani and M.C. Nicoli (2016), 'Technological and consumer strategies to tackle food wasting', Food Engineering Reviews, 8(4), 457-67.

McMichael, P. (2009), 'The world food crisis in historical perspective', Monthly Review, 61(3), 32-47.

Mena, C., B. Adenso-Diaz and O. Yurt (2011), 'The causes of food waste in the supplier-retailer interface: Evidences from the UK and Spain', Resources, Conservation and Recycling, 55(6), 648-58.

Ministero dell'Ambiente (2014), PINPAS - Piano Nazionale di Prevenzione degli sprechi Alimentari [National Plan for Food Waste Prevention], accessed 9 October 2018 at www.minambiente.it/sites/default/files/ archivio_immagini/Galletti/Comunicati/PINPAS\%2010\%20MISURE \%20PRIORITARIE\%205\%20GIUGNO\%202014.pdf.

Mourad, M. (2016), 'Recycling, recovering and preventing "food waste": Competing solutions for food systems sustainability in the United States and France', Journal of Cleaner Production, 126, 461-77.

Parfitt, J., M. Barthel and S. Macnaughton (2010), 'Food waste within food supply chains: Quantification and potential for change to 2050', Philosophical Transactions of the Royal Society B: Biological Sciences, 365(1554), 3065-81.

Pawson, R. (2002), 'Evidence-based policy: The promise of realist synthesis', Evaluation, 8(3), 340-58.

Pawson, R. (2006), 'Digging for nuggets: How "bad" research can yield "good" evidence', International Journal of Social Research Methodology, 9(2), 127-42.

PINPAS (2015), 'La donazione degli alimenti invenduti: Verso la semplificazione normativa' [Donation of unsold food: Towards legal simplification], accessed 9 October 2018 at http:/www.minambiente.it/sites/default/ files/archivio_immagini/Galletti/Comunicati/alma_mater_bologna/Position \%20paper\%20sulla\%20donazione\%20degli\%20alimenti\%20invenduti.pdf.

Pirani, S.I. and H.A. Arafat (2016), 'Reduction of food waste generation in the hospitality industry', Journal of Cleaner Production, 132, 129-45.

Priefer, C., J. Jörissen and K.R. Bräutigam (2016), 'Food waste prevention in Europe - a cause-driven approach to identify the most relevant leverage points for action', Resources, Conservation and Recycling, 109, 155-65.

Rubino (2017), 'Spreco alimentare: L'Italia più virtuosa un anno dopo l'approvazione della legge' [Food waste: Italy more virtuous one year after new law approved], Repubblica, accessed 9 October 2018 at http://www.repubblica .it/politica/2017/09/14/news/spreco_alimentare un anno_dopo-175461997/.

Schneider, F. (2013), 'The evolution of food donation with respect to waste prevention', Waste Management, 33(3), 755-63.

Thøgersen, J. (1996), 'Wasteful food consumption: Trends in food and packaging waste', Scandinavian Journal of Management, 12(3), 291-304. 
Thyberg, K.L. and D.J. Tonjes (2016), 'Drivers of food waste and their implications for sustainable policy development', Resources, Conservation and Recycling, 106, 110-23.

Toia, P. (2018), Dallo spreco al dono [From Waste to Gift], e-book, accessed 9 October 2018 at http://www.patriziatoia.info/images/ebooks/ Dallo_spreco_al_dono.pdf.

United Nations (2015), Sustainable Development Goals, accessed 9 October 2018 at https://www.un.org/sustainabledevelopment/sustainable -development-goals/.

Visschers, V.H., N. Wickli and M. Siegrist (2016), 'Sorting out food waste behaviour: A survey on the motivators and barriers of self-reported amounts of food waste in households', Journal of Environmental Psychology, 45, 66-78. 